\title{
Backlash analysis of RV reducer based on Error Factor Sensitivity and Monte-Carlo Simulation
}

\author{
Y. G. Sun ${ }^{1}$, X. F. Zhao ${ }^{1,2}$, F. Jiang ${ }^{1}$, L. Zhao ${ }^{1}$, D. Liu ${ }^{1}$ and G. B. Yu ${ }^{1 *}$ \\ ${ }^{1}$ College of Mechanical and Power Engineering, Harbin University of Science and \\ Technology, Harbin, Heilongjiang Province, China 150080 \\ ${ }^{2}$ Harbin Aviation Industry (Group) Co., Ltd, Heilongjiang Province, China 150066 \\ * Corresponding author: G.B. Yu, yu_ccna@163.com
}

\begin{abstract}
Error factors of $R V$ reducer are not completely considered, leads to backlash precision is limited, so an improved backlash estimation model is proposed, $R V$ reduce structure and working principle is deeply analyzed, a variety of error factors are considered, and the backlash estimation model is improved according to error propagation. Furthermore, sensitivity of all the error factors are analyzed, RV reducer backlash is obtained through Monte-Carlo simulation, and the simulation results are compared with the traditional computation results. It is conductive to taking fix action in the design stage, reducing backlash, improving the transmission accurac?
\end{abstract}

Keywords: RV reducer; backlash.sensitivity analysis; Monte-Carlo simulation

\section{Introduction}

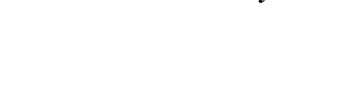

$\mathrm{RV}$ reducer is widely used in national defense, aerospace and industrial production. It has been a main topic of much discussion as its transfer accuracy is seriously affected by backlash. Blanche studied rotating accuracy of cycloid and lantern gear reducer using pure geometry method $11 . \mathrm{Wu}$ Yongkuan established mathematical model for the geometric backlash of high accurate RV reducer used in robot [2]. Han Linshan discussed dynamic transmission accuracy of the RV reducer [3-4]. However, all the error factors of RV reducer were not completely considered, as a result, the actual situation of RV reducer was not truly reflected. Therefore ail the error factors from multi sources were comprehensively analyzed, and exact results of RV reducer backlash were given. What' $\mathrm{s}$ more, the sensitiveness of the error factors was discussed, and the RV reducer backlash was simulated through Monte-Carlo method. By this way, it could make a great contribution to take corrective measures to reduce backlash to improve the transmission accuracy at the design stage.

\section{Structure of RV Reducer}

The rated input speed of RV reducer is $15 \mathrm{r} / \mathrm{min}$, and rated output torque is $784 \mathrm{Nm}$. Mechanism block diagram of the reducer is shown in Figure 1, which is mainly composed of input gear, three planet gears, three crankshafts, two cycloidal and pin gear pairs, hold flange and output.

The RV reducer is a 2-stage reduction gear. The first stage is spur gear reduction. An input gear engages with and rotates spur gears that are coupled to crankshafts. The second stage is epicyclical gear reduction. Crankshafts driven by the spur gears cause 
an eccentric motion of two epicyclical gears called RV gears that are offset 180 degrees from one another to provide a balanced load. The eccentric motion of the RV gears causes engagement of the cycloidal gear teeth with cylindrically pins locate d around the inside edge of the case. In the course of one revolution of the crankshafts the teeth of the RV gear move the distance of one pin in the opposite directions of the rotating cranks. The motion of the RV gear is such that the teeth remain in close contact with the pins and many teeth share the load simultaneously. The case is fixed, so the shaft is output.

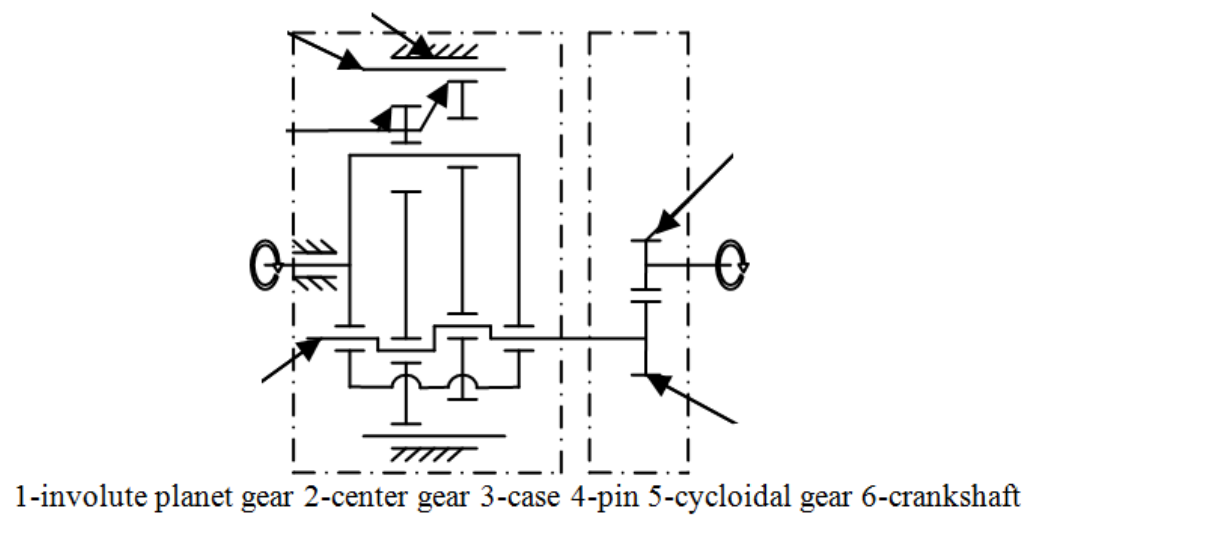

Figure 1. $\mathrm{RV}$ reducer transmission diagram

\section{RV Reducer Backlash Analysis}

\subsection{Influencing factors of backlash}

The influencing factors of the involute planetary transmission and the cycloid planetary transmission are as follows:

(1) The involute transmission s error factors

1) Deviation of base tangent length

2) Deviation of central circular

3) Radial run-out

4) Parallelis $m$ of axis

5) Radial composite error (including tooth profile error, cumulative pitch error, tooth alignment error)

6. Eccentricity of rolling bearing

(2) The cycloidal transmission's error factors

1) Mending tooth shape of the cycloidal gear

2) Total cumulative pitch error of the cycloidal gear

3) Radial run-out of the cycloidal gear

4) Radius of the circle error of the pin gear

5) Radius of the pin gear error 
6) Fit of clearance of the gear pin and hole

7) Total cumulative pitch error of the pins

8) Mending tooth shape error of the cycloidal gear

9) Clearance of crankshaft

10) Eccentricity of crankshaft

\subsection{Mathematical model of backlash}

The backlash of RV reducer is composed of the involute planetary transmission error and the cycloid planetary transmission error. According to the relationship of error transmission, the mathematical model of backlash is shown in (1),

$$
\Delta \varphi=\frac{180 \times 60 \Delta j_{1}}{i_{16}^{5} \pi r_{1}}+\frac{180 \times 60}{\pi a z_{c}} \Delta j_{2}+\frac{180 \times 60}{\pi a_{0}} \Delta j_{3}
$$

Where $\Delta \phi$ is total backlash of transmission system to the output shaft, $\Delta \mathrm{j} 1$ is the involute gear transmission part of the backlash, $\Delta \mathrm{j} 2$ is the cycloidal gear transmission part of the backlash, $\Delta \mathrm{j} 3$ is rolling bearing part of the backlash, is reduction ratio of $\mathrm{RV}$ reducer.

Obviously, the errors of all the influencing factors should be calculated firstly. The backlash expressions are listed in Table 1.

\begin{tabular}{|c|c|c|c|c|c|}
\hline No & Error factors & aeklash & No & Error factors & Backlash \\
\hline 1 & & & & $\begin{array}{l}\text { Moving distance } \\
\text { modification }\end{array}$ & $-2 \Delta r_{p} \sqrt{1-K_{1}^{2}}$ \\
\hline & & & 13 & $\begin{array}{l}\text { Radial run-out of } \\
\text { the cycloidal gear }\end{array}$ & $\frac{F_{r}}{4}$ \\
\hline & & & 14 & $\begin{array}{l}\text { Radius of the } \\
\text { circle error of the } \\
\text { pin gear }\end{array}$ & $\delta r_{p} \sqrt{1-K_{1}^{2}}$ \\
\hline & & $\frac{1}{2} f_{x} \tan \alpha$ & 15 & $\begin{array}{l}\text { Radius of the pin } \\
\text { gear error }\end{array}$ & $\delta r_{r p}$ \\
\hline & & $\frac{1}{2} f_{y}$ & 16 & $\begin{array}{c}\text { Fit of clearance of } \\
\text { the gear pin and } \\
\text { hole }\end{array}$ & $\frac{d_{j \max }-d_{j \min }}{2}$ \\
\hline & $\begin{array}{l}\text { Tooth profile } \\
\text { error }\end{array}$ & $\frac{f_{f}}{\cos \alpha}$ & 17 & $\begin{array}{l}\text { Pitch error of the } \\
\text { pins }\end{array}$ & $\frac{F_{p}^{\prime} K_{1}}{2}$ \\
\hline 7 & $\begin{array}{l}\text { Cumulative } \\
\text { pitch error }\end{array}$ & $f_{p t}$ & 18 & $\begin{array}{l}\text { Modification } \\
\text { error }\end{array}$ & $\delta \Delta r_{r p}$ \\
\hline 8 & $\begin{array}{c}\text { Tooth } \\
\text { alignment error }\end{array}$ & $f_{\beta}$ & 19 & $\begin{array}{l}\text { Moving distance } \\
\text { modification error }\end{array}$ & $\delta \Delta r_{p} \sqrt{1-K_{1}^{2}}$ \\
\hline 9 & $\begin{array}{l}\text { Eccentricity of } \\
\text { rolling bearing }\end{array}$ & $2 e_{g} \tan \alpha$ & 20 & $\begin{array}{l}\text { Clearance of } \\
\text { crankshaft }\end{array}$ & $\frac{\Delta u_{\max }-\Delta u_{\min }}{2}$ \\
\hline 10 & $\begin{array}{l}\text { Pitch error of } \\
\text { the cycloidal } \\
\text { gear }\end{array}$ & $F_{p} K_{1}$ & 21 & $\begin{array}{l}\text { Eccentric error of } \\
\text { crankshaft }\end{array}$ & $2 k_{n} \delta a$ \\
\hline 11 & $\begin{array}{c}\text { Modification } \\
\text { of equidistance }\end{array}$ & $2 \Delta r_{r p}$ & & & \\
\hline
\end{tabular}


Thus the Eq. (1) can be rewritten,

$$
\Delta \varphi=\frac{180 \times 60}{i_{16}^{5} \pi r_{1}} \sum_{i=1}^{8} \Delta j_{i}+\frac{180 \times 60}{\pi a z_{c}} \sum_{i=9}^{19} \Delta j_{i}+\frac{180 \times 60}{\pi a_{0}} \sum_{i=20}^{21} \Delta j_{i}
$$

\subsection{Calculation of backlash}

The circumference backlash $\Delta E_{s}$ caused by deviation of base tangent length can be written in (3)

$$
j_{t \Delta E_{s}}=-\frac{\Delta E_{s}}{\cos \alpha}
$$

Where Ess and Esi are upper deviation and lower deviation. $\Delta$ Es is noted as a candom variable, which obeys normal distribution according to engineering experience. Shown in Fig.2.The digital features of $\Delta$ Es are shown in (4) and (5),

$$
\begin{gathered}
\mu\left(\Delta E_{s}\right)=-\frac{E_{s s}+E_{s i}}{2 \cos \alpha} \\
\sigma\left(\Delta E_{s}\right)=-\frac{E_{s s}+E_{s i}}{6 \cos \alpha}
\end{gathered}
$$

\section{Figure 2. Statistical distribution of the deviation}

To suppose all the error factors are randon variables which obey Normal distribution. To refer GB2363-90 and IB 10419-2005, tolerance of all the factors are substituted into equations above. The results are soyn in Table 2.

Digital featare in table 2 were introduced into Eq. (2), and then the total system backlash is obtained, which is $\varphi \sum=\mu \sum+3 \alpha \sum=6.12 \pm 1.77(\operatorname{arcmin})$. The expectation is $6.12(\operatorname{arcmin})$, and the fluctuation range from 435 ( $\operatorname{arc} \mathrm{min})$ to $7.89(\operatorname{arc} \mathrm{min})$.

\subsection{Sensitivity analysis}

Each erron caused by the influencing factor is considered to be a random variable, and is recorded as $x=\left[x_{1}, x_{2}, \ldots, x_{k}\right]$, then $\Delta x=\left[\Delta x_{1}, \Delta x_{2}, \ldots, \Delta x_{k}\right]$. Backlash of RV reducer can be denoted as $\varphi(x)=\varphi\left(x_{1}, x_{2}, \ldots, x_{k}\right)$. From above, the sensitivity of each error factor can be written as follows:

$$
S_{i}=\nabla \varphi(x)=\left[\frac{\partial \varphi}{\partial x_{1}}, \frac{\partial \varphi}{\partial x_{2}}, \ldots, \frac{\partial \varphi}{\partial x_{k}}\right]=\left[S_{1}, S_{2}, \ldots, S_{k}\right]
$$


Table 2. Digital feature and results of the error factors

\begin{tabular}{|c|c|c|c|}
\hline \multirow{2}{*}{ No. } & \multirow{2}{*}{ Error factors } & \multicolumn{2}{|c|}{ Digital feature } \\
\hline & & $\mu$ & $\sigma$ \\
\hline 1 & $\begin{array}{l}\text { Deviation of base } \\
\text { tangent length }\end{array}$ & $-\frac{E_{s s}+E_{s i}}{2 \cos \alpha}=-15.963$ & $-\frac{E_{s s}+E_{s i}}{6 \cos \alpha}=-5.321$ \\
\hline 2 & $\begin{array}{l}\text { Deviation of } \\
\text { central circular }\end{array}$ & 0 & $\frac{1}{3} \Delta f_{a} \tan \alpha=1.577$ \\
\hline 3 & Radial run-out & 0 & $\frac{F_{\mathrm{t}} \tan \alpha}{3}=2.184$ \\
\hline 4 & $\begin{array}{l}\text { Parallelism of } \mathrm{x} \\
\text { axis }\end{array}$ & $\frac{1}{2} f_{x} \tan \alpha=1.902$ & $\frac{1}{6} f_{x} \tan \alpha=0.364$ \\
\hline 5 & $\begin{array}{l}\text { Parallelism of y } \\
\text { axis }\end{array}$ & $\frac{1}{2} f_{y}=1.5$ & $\frac{1}{6} f_{y}=0.5$ \\
\hline 6 & tooth profile error & $\frac{f_{f}}{\cos \alpha}=9.578$ & $\frac{f_{f}}{3 \cos \alpha}=3.193$ \\
\hline 7 & $\begin{array}{l}\text { cumulative pitch } \\
\text { error } \\
\end{array}$ & 0 & \\
\hline 8 & $\begin{array}{l}\text { Tooth alignment } \\
\text { error }\end{array}$ & 0 & \\
\hline 9 & $\begin{array}{l}\text { Eccentricity of } \\
\text { rolling bearing }\end{array}$ & 0 & \\
\hline 10 & $\begin{array}{l}\text { Total cumulative } \\
\text { pitch error }\end{array}$ & & \\
\hline 11 & $\begin{array}{l}\text { Modification of } \\
\text { equidistance }\end{array}$ & & \\
\hline 12 & $\begin{array}{l}\text { Moving distance } \\
\text { modification }\end{array}$ & & \\
\hline 13 & $\begin{array}{l}\text { Radial run-out } \\
\text { the cycloidal ge }\end{array}$ & & $\frac{F_{r}}{12}=1.917$ \\
\hline 14 & $\begin{array}{l}\text { Radius of the } \\
\text { circle error of the } \\
\text { pin gear }\end{array}$ & & $\frac{1}{3} \delta r_{p} \sqrt{1-K_{1}^{2}}=1.241$ \\
\hline 15 & $\begin{array}{l}\text { ditus of the pin } \\
\text { gear error }\end{array}$ & 0 & $\frac{1}{3} \delta r_{r p}=1.333$ \\
\hline & & $\frac{\delta_{j \max }-\delta_{j \min }}{2}=8.75$ & $\frac{\delta_{j \max }-\delta_{j \min }}{6}=2.92$ \\
\hline 17 & $\begin{array}{c}\text { Total cumulative } \\
\text { pitch error of the } \\
\text { pins }\end{array}$ & $\frac{F_{p}^{\prime} K_{1}}{2}=18$ & $\frac{F_{p}^{\prime} K_{1}}{6}=6$ \\
\hline & $\begin{array}{l}\text { Modification of } \\
\text { equidistance error }\end{array}$ & 0 & $\frac{\delta \Delta r_{r p}}{3}=0.667$ \\
\hline & $\begin{array}{l}\text { Moving distance } \\
\text { modification error }\end{array}$ & 0 & $\frac{\delta \Delta r_{p}}{3} \sqrt{1-K_{1}^{2}}=4.963$ \\
\hline 20 & $\begin{array}{c}\text { Clearance of } \\
\text { crankshaft }\end{array}$ & $\frac{\Delta u_{\max }+\Delta u_{\min }}{2}=2.5$ & $\frac{\Delta u_{\max }-\Delta u_{\min }}{6}=0.5$ \\
\hline 21 & $\begin{array}{c}\text { Eccentric error of } \\
\text { crankshaft }\end{array}$ & 0 & $\frac{2 k_{n} \delta a}{3}=3.3 \times 10^{-5}$ \\
\hline
\end{tabular}

Normalized the sensitivities by (7), and their weight are obtained.

$$
g_{i}=\frac{S_{i}}{\sum_{i=1}^{k} S_{i}}
$$


The results are listed in Table 3.

Table 3. Sensitivities and weights of error factors

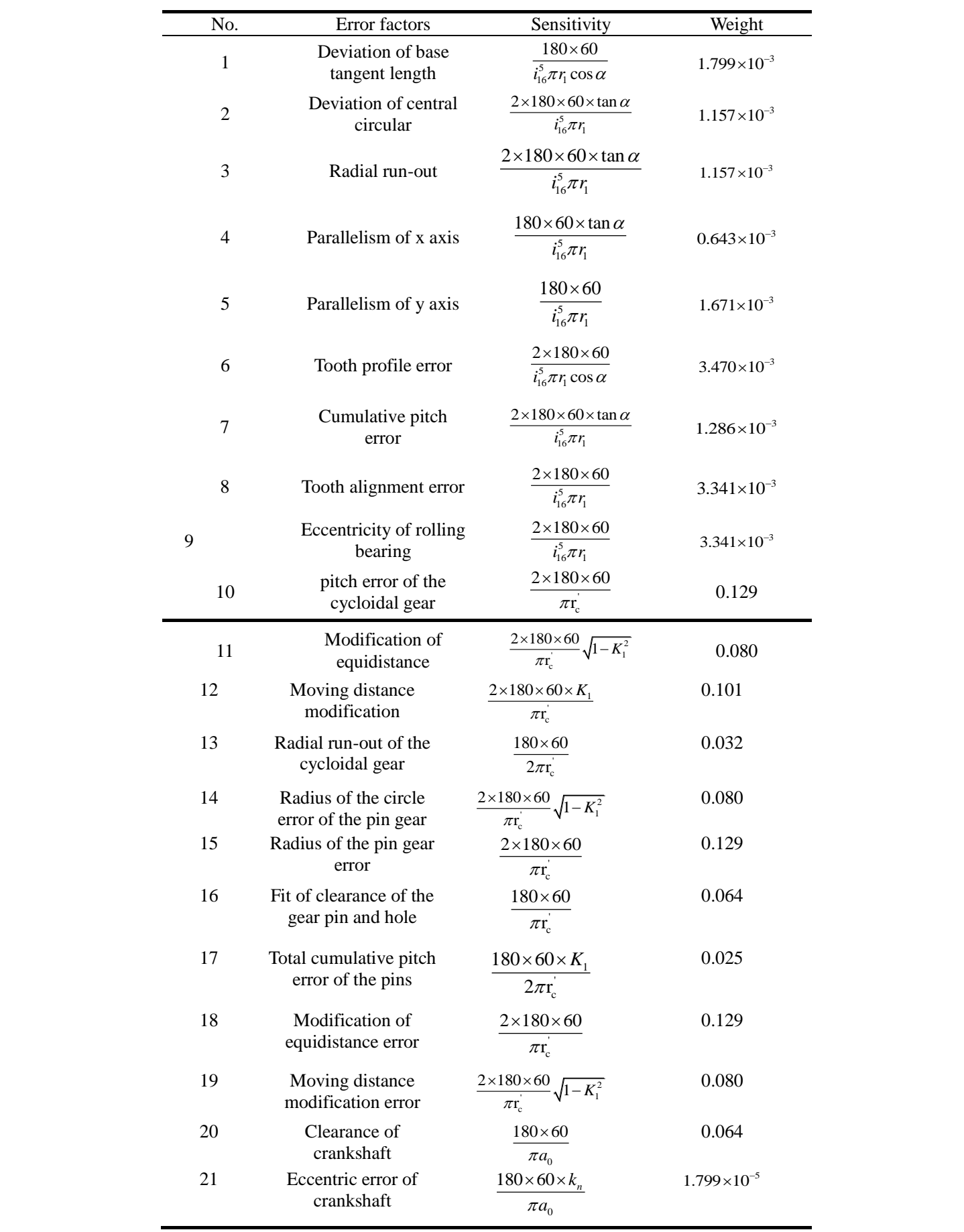


Conclusions are obtained from Table 3,

(1) The error factors in 1st stage have less influence on system backlash. Their sensitivity values are less than 0.1 .

(2) The error factors in 2nd stage have a major influence on system backlash, especially radius of the pin gear error, total cumulative pitch error of the cycloidal gear and modification of equidistance error. These factors with the largest sensitivity are the greatest-affected factors. However, the sensitivity of eccentric of crankshaft is very small. So the system backlash is lighted influenced by them, which can be ignored.

(3) To find the important influencing error factors of backlash is in favor of seizing the main contradiction during the design. What' s more, we can target to take corrective action and reduce system backlash quickly efficiently.

\section{RV Reducer Backlash Monte-Carlo Simulation}

Random number is generated by Monte Carlo simulation according to certain probability distribution [5]. In fact, the RV reducer backlash is combined of several kinds of random variables which obey normal distribution. It' $\mathrm{s}$ difficult to determine the system backlash distribution and parameters composed of different probability distribution by traditional method. As a result, influences cased by multiplê error factors are considered comprehensively, Monte Carlo simulation is ut lized to simulate all kinds of situation may appear. By this way, the RV system backlash can be Computed quickly and easily. It can provide decisions basis for the backlasin control.

\subsection{Monte Carlo simulation procedure}

(1) To determine the probability distribution and digital feature, and calculate their inverse transformation.

(2) To program by MATLAB, using uniform distributed random number generator to generate 1000 random numbers. Substitute the digital feature of the error favors into inverse transformation, and then the yalues of simulation are taken.

(3) The simulation results are obtained by 1000 sampling values of RV transmission backlash.

\subsection{Inverse transformation of error factors}

If $\mathrm{R} 1$ and $\mathrm{R} 2$ are both random variable of uniform distribution in $[0,1]$, the inverse transformation generated normal distribution variable $\mathrm{X}$ can be written by (8)

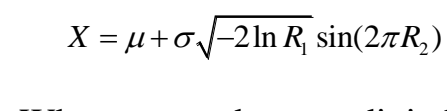

Where $\mu$ and $\sigma$ are digital feature of error factors[6].

\section{Results Analysis}

Monte-Carlo simulation is carried out in MATLAB according to the methods above, as shown in Figure 4. 

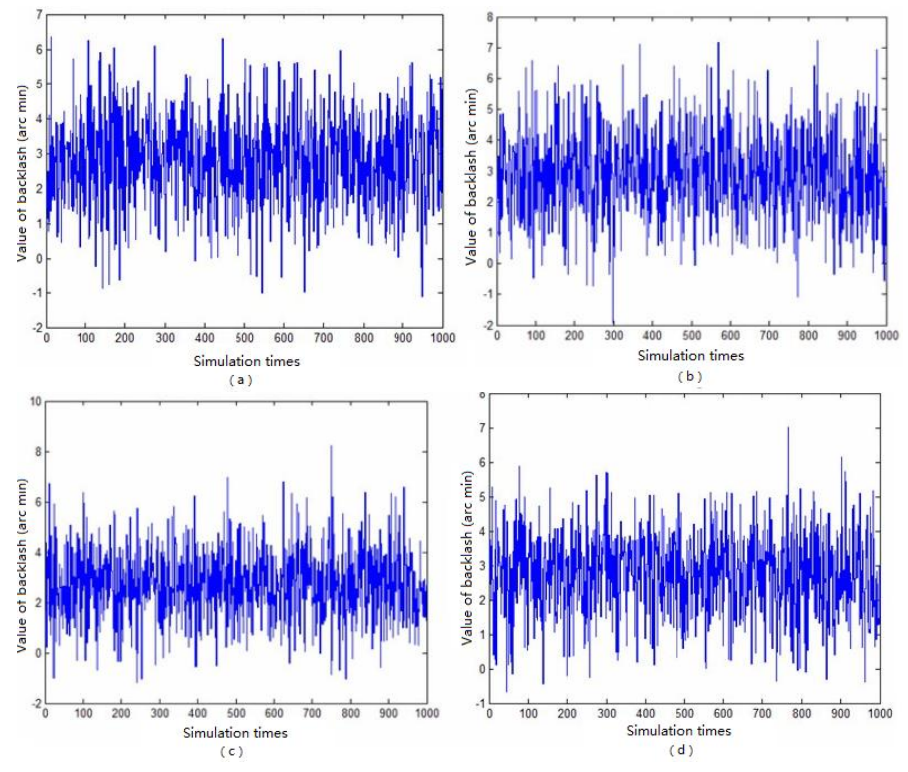

Figure 4. Simulation results

(a) In the 1st Figure, when the precision (nt the two stages is 6-grade, the system backlash is less than 8 (arc $\min )$ in all probability which is consistent with the result of direct calculation. From the actually simulation, system backlash range is from 2(arc min) to $6(\operatorname{arc} \min )$.

(b) In the 2nd Figure, if the precision is 6-grade in the second stage and the precision in the first stage is 5-grade. Total backrash is improyed little.

(c) In the 3rd Figure, if the precision s 5rade in the second stage and the precision in the first stage is 6-grade. The backlash change heavily. Obviously, the accuracy of the second stage plays ân important role in system backlash.

(d) In the 4th Figure, the precision of error factors which has larger sensitivity are changed to be 5 grade according to Table 2 , the system backlash reduced greatly.

\section{Conclusion}

In this paper, structure of the RV reducer and its backlash has been researched. Furthermore, sensitivity of error factors that influence RV transmission backlash has been analyzed. With the help of statistical knowledge, each factor' s digital feature has been deduced. The backlash of RV reducer is simulated by using Monte-Carlo. Although the simulation has error, system backlash can be predicted in the design stage, especially for mass production, it has very practical significance.

\section{Acknowledgements}

This research was supported by the Key Program of National Natural Science Foundation of Heilongjiang No.ZD201309, And supported by the Harbin City Key Technologies R \& D Program under Grant No. 2011AA1BG059, and Education Department Project of Heilongiiang Province (No. 11551083), and the fund project of the high tech industry of Harbin (No. 2012DB2AP005). 


\section{References and Notes}

[1] J. G. Blanch and D. C. H. Yang, "Cycloid drives with machining tolerances", Journal of Mechanisms, Transmissions, and Automation in Design, vol. 111, no. 9, (1989), pp. 337-344.

[2] W. Yongkuan, Z. Jianyun, C. Tianqi and L. Lixing, "The Analysis Research of the Geometric Lost Motion of High Accurate RV Reducer Used in Robot”, Journal of Dalian institute of railway technology, vol. 20, no. 2, (1999), pp. 24-27.

[3] G. Haijun, "Accuracy of Analysis and Simulation Study of the 2KV Type Cycloid Drive", Northwestern Polytechnic University.

[4] H. Linshan, S. Yunwen, D. Haijun, "The Oretical Research on Dynamic Transmission Accuracy for 2K-VType Drive", Chinese journal of mechanical engineering, vol. 43, no. 6, (2007), pp. 81-86.

[5] Z. Benren, "Monte-Carlo methods introduction", Jinan: Shangdong University Press, (1987).

[6] C. Wenhua, Z. Haifeng and F. Xiaoyan, "Monte-Carlo Simulation Analysis of Transmission Error for Gear Drive Systems", Journal of Scientific Instrument, vol. 25, no. 4, (2004), pp. 435-437.

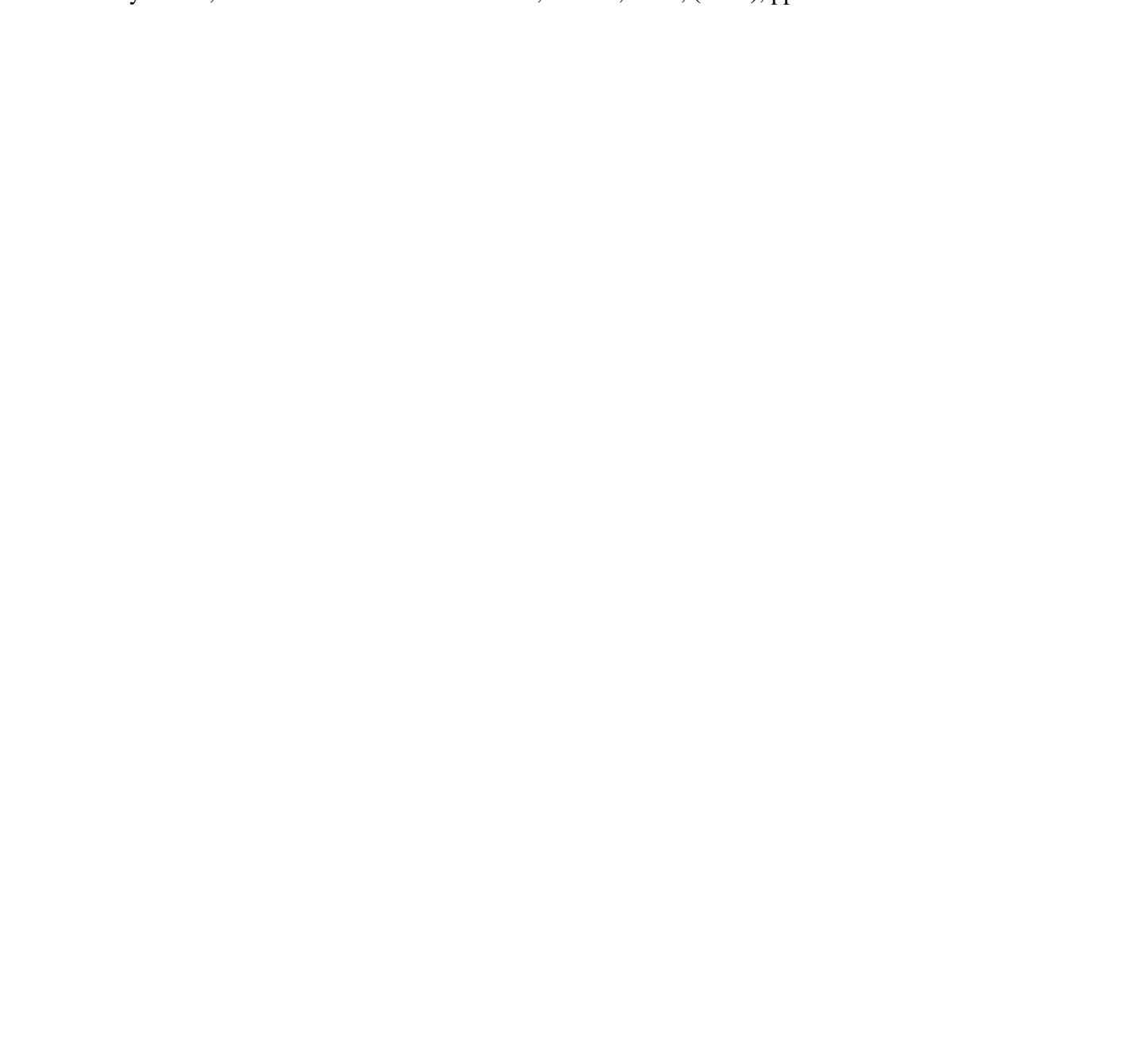


International Journal of Hybrid Information Technology

Vol.7, No.2 (2014)

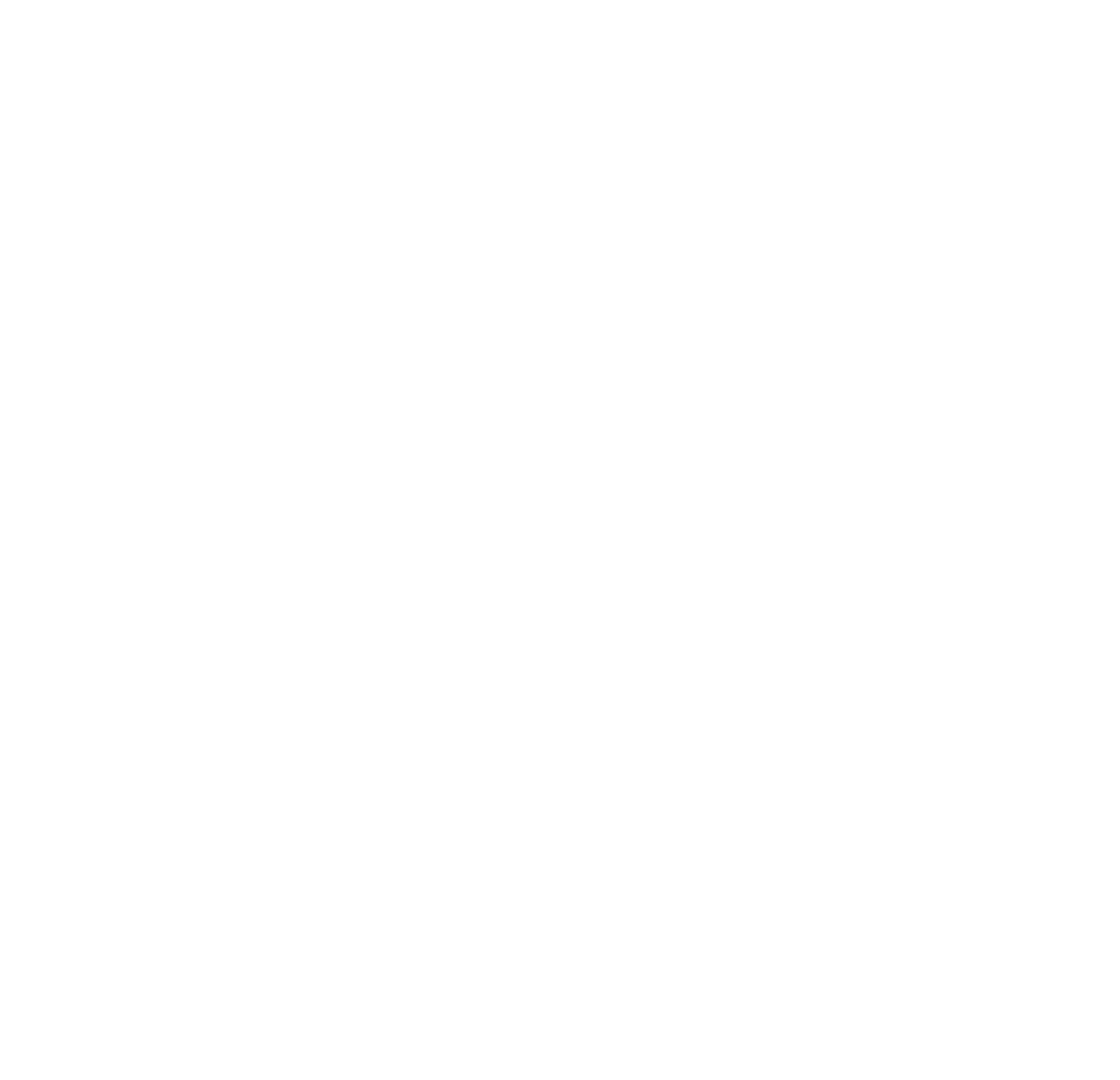

